providing the local linkages. Together with the example of locally branded products, this raises the question about the direct transferability of western models of rural development in this region. The western European model, where rural discourses are influenced by the rural idyll, counterurbanisation and consumerism, has created policy approaches such as Leader where local communities are expected to play a key role in promoting development from within. However, we might question whether these are pushing some Central European regions to adopt approaches that are paradoxically less well suited to their localities, at least in the short to medium term.

\title{
Handbook of Research on Entrepreneurship. What We Know and What We Need to Know
}

Edited by Fayolle, $A$.

Edward Elgar Publishing Ltd,

Northampton, MA

2014

433pp.

Review DOI 10.1108/IJEBR-12-2014-0234

Entrepreneurship has been a field of research that constantly has looked at new horizons to enlarge its understanding. In this sense, several scholars have contributed by doing research in different fields of knowledge.

It was with great interest that I started to read this Handbook of Research on Entrepreneurship edited by Alain Fayolle. I was, of course, curious to know how the entrepreneurship research is going on, and what the purposes of the contributors on entrepreneurship are. My interest was further aroused when I read the introduction to the book and find the organization of the material considering different groups that gather interesting approaches of entrepreneurship.

The book is based on the contributions of several scholars from the USA and Europe. The text is made up of seventeen chapters organized in four main parts. Chapter 1 is the starting point of the book that discusses the advancement of entrepreneurship. And, the rest of this handbook is digging out into four different perspectives organized in four parts that contained four chapters in each. Part 1 is devoted to contributions regarding the "redesigning entrepreneurship research"; followed by Part II where contributors focussed on "crossing the fields and the concepts"; in Part III contributors focussed on "embedding knowledge in insightful concepts and domains" and in Part IV authors present "exploring (new) or revising (old) research topics."

Part I of the book includes four chapters in which the authors discus the redesigning entrepreneurship research. In Chapter 2 William Gartner argues about the nature of entrepreneurship as a field of research and about the future of entrepreneurship scholarship. Gartner based on several efforts to define what entrepreneurship is realizing about the idea of "organizing emergence." By this concept it is assumed that the nature of entrepreneurship is captured. The author also highlights that organizing emergence is occurring in a variety of contexts where scholars are in some sense organizing the entrepreneurship knowledge. Despite all the efforts and contributions of 
IJEBR 21,3

504

scholars, according to Gartner, there is no expectation of the development of a grand theory of entrepreneurship or a framework that can organize entrepreneurship research. So, the author suggests that scholars could focus on the development of entrepreneurship in their narrow community but connect to broader network of entrepreneurship scholars. In Chapter 3 Hans Landström focusses on developing a "history of entrepreneurship research" where the main objective is to give an historical review of the formation of entrepreneurship as an intellectual field. This chapter is interesting because the author analytically describes the historic evolution of the entrepreneurship research. I am consistent with Hans Landström about the nature of entrepreneurship. He points out that entrepreneurship is multifaceted phenomenon that requires multiple concepts and theories sometime imported from other field of knowledge. I think this chapter is useful for future scholars in entrepreneurship research such as post-graduate students since it gives a panorama of the historic view of entrepreneurship research. In Chapter 4 Bengt Johannisson presents "entrepreneurship, theory and/or practice?" where the author highlights his point of departure of how he sees entrepreneurship. For Johannisson entrepreneurship is a collective phenomenon, as creative organizing of thoughts, actions and people. Moreover, the author argues three main concepts: theory, practice and art which are linked to the concept of entrepreneuring. This concept is based on analogies from children actions in the life. Thereby, this chapter is interesting because the author is based on simple analogies found in his dairy life. I think Johannisson ideas' have some relation with Gartner when suggest that scholars may consider their expertise in their narrow community. Finally in Chapter 5 "the landscape of qualitative methods in entrepreneurship: a European perspective" is developed by Helle Neergaard. I believe this is an interesting chapter regarding the qualitative methodologies used to analyze entrepreneurship. It is highlighted that qualitative methodologies should be used in entrepreneurship studies. This is because qualitative techniques give opportunities to analyze stories and contemporary phenomena in order to enhance the understanding of entrepreneurship.

Part II of the book includes four chapters where the authors presented contributions related to studies in which prevails the crossing of fields of knowledge. In Chapter 6 "exploring the intersection of gender, feminism and entrepreneurship" is presented by Colette Henry and Susan Marlow. The authors developed an overview of the literature on female entrepreneurship and assess its progress using the feminist approach. According to the authors the research on female entrepreneurship has moved from trends that only recognized gender as a variable to more theoretically sophisticated work. This advancement recognizes gender as a social construct generating challenges for business women owners and also for future research. Moreover, authors suggest the critical analysis in the field of female entrepreneurship in order to challenge the normative epistemology inherent within the entrepreneurship discipline. In Chapter 7 Benson Honig and Bruce Martin focus on "entrepreneurship education." The authors contributed offering a theory of learning which is relevant for entrepreneurship, according them. Moreover, the pedagogical theory and entrepreneurship education is discussed regarding its implications. Authors pointed out the importance of educating entrepreneurs therefore invoke the reworking of the entrepreneurship syllabus. Particularly, I think this study is useful for practitioners in the field of education and entrepreneurship, so higher education institutions could take advantage from this study.

Chapter 8 presents "culture and entrepreneurship: empirical evidences for direct and indirect effects" conducted by James Hayton and Gabriella Cocciotti. This study is a 
review about the variety of knowledge on culture's consequences for entrepreneurship. This study could be useful for academic that entering on the field of culture and entrepreneurship because it is a compilation of previous studies on the issue. Chapter 9 is dedicated to review the family and entrepreneurship field of knowledge. This study is developed by Lucie Bégin and Alain Fayolle. The focus is to develop research propositions around the exploration of both the interplay between the family and entrepreneurship and between entrepreneurship and family business. Also, this study contributes defining family entrepreneurship as a research field. The propositions generated are interesting but a big challenge is triggered to test them empirically in future research studies. All the studies presented in this chapter are interesting because reveal the magnitude of entrepreneurship when linked to other fields of knowledge.

Part III includes four chapters that focus on embedding knowledge in (insightful) concepts and domains. Chapter 10 presents "Entrepreneurial orientation: disposition and behavior" developed by Brian S. Anderson and Jeffrey G. Covin. This chapter is interesting because the authors critique the trends on EO highlighting that researchers have overlooked the role of senior manager disposition. So, the authors suggest new paths for future research on EO. It is important to conceptually distinguish dispositions from behaviors in the EO conversation to understand the entrepreneurial firm. In Chapter 11 a "review on effectuation" is conducted by Stuart Read and Sharon Dolmans. The authors review previous studies on effectuation based on more than 100 papers published in peer-reviewed journals. This is an interesting study that provides a roadmap through the extant body of effectuation work in order to look for intersections and possible next destinations. It is helpful for future researchers that would research on this issue. Still on the subject of embedding knowledge, Kelly Shaver presents the "psychology of entrepreneurial behavior" in Chapter 12. This chapter presents the psychological side of entrepreneurship which is the entrepreneurial behavior of individuals. The author suggested that motivations and emotions are great topics for future research. Also, some methods are pointed out as a need for research the entrepreneurial behavior. Chapter 13, the last of this section is related to the "entrepreneurial finance" conducted by Mike Wright and Philippe Desbrières. This paper is interesting and important since touches a main issue in entrepreneurship, the finance support to create a business. So, the authors examine the challenges to entrepreneurs in obtaining finance for firms. Different sources of finance used by entrepreneurs are reviewed.

Part IV is the last part of this book. It includes four chapters that focus on (re) exploring new research topics. Chapter 14 is dedicated to "Rural enterprise and entrepreneurship" developed by Gerard McElwee and Robert Smith. The authors highlight a lack of studies on rural enterprises for this reason a typology is developed. Also, they pointed out that there is not a clear definition of rural enterprise. Differences between rural and urban enterprises are examined as well as the role of the rural entrepreneur and the drivers to create a rural enterprise. Moreover, a conceptual framework that classified rural business is presented. In general, this chapter can contribute to understand the rural enterprises however I feel the lack of previous studies on rural entrepreneurship (Bryant, 1989; Goetz et al., 2010; Stathopoulou et al., 2004). Still in this part of the book, "Business incubation and incubator mechanisms" are presented by Sarfraz Mian in Chapter 15. When I began to read this chapter I feel the lack of the introduction of this subject. The author called the first section of introduction but the content is not the appropriate for an introduction. Despite of this, I think this chapter presents a definition of incubation, a brief history and growth of incubators and makes a review of literature on business incubation. This chapter is a 
IJEBR summary of previous studies on business incubators. The reader can find some case 21,3 studies as example on business incubator. In Chapter 16, "Illegal rural enterprise" is examined by Gerad McElwee, Robert Smith and Peter Somerville. Illegal enterprises are defining and characterized by the authors and a framework is developed to understand illegal rural enterprises. An interesting topic such as illegality is pointed out by the authors. So, after reading this chapter I would also like to know why is important to highlight illegality in rural context rather in the urban context. To understand this issue is important for governments, policy makers and also scholars. This chapter makes a call to think in the dark side of entrepreneurship. Finally, in this part of the book, Saulo Dubard Barbosa presents a "revisiting entrepreneurship research from a decision making perspective" in Chapter 17. It is true that entrepreneurship has implicitly and explicitly relationship with decision-making process. So, the author revisited entrepreneurship research from a decision-making point of view. The Kuhnian notion is used to define the subject. Moreover, the author uses four dimensions derived from Katz and Gartner (1988) that are used to articulate seven questions related to the entrepreneurial decision making: who, when, where, what, why, how and what for? This framework is interesting since it could be applied to any kind of decision within the entrepreneurial process. Personally, I think this chapter could be useful for academics interested in research on entrepreneurial decision making.

I believe this book is interesting for academy field and for policy makers. Really I appreciate the effort made by authors of the book. Particularly, I believe that papers in Part I try to contribute to the understanding of entrepreneurship because authors suggest new ways of lead with research on entrepreneurship. However, the rest of the book sounds something already known but also it is seen the effort to contribute to better understand entrepreneurship. For instance, Part II has only included four examples of crossing field when in reality there are more than these such as for example immigrant entrepreneurship, social entrepreneurship, minority entrepreneurship, among others. In general the book is worthwhile reading for entrepreneurship scholars because there are some interesting gaps to be exploited as future research lines.

\section{Rocío Aliaga-Isla Universidad Autonoma de Barcelona, Barcelona, Spain}

\section{References}

Bryant, C.R. (1989), "Entrepreneurs in the rural environment", Journal of Rural Studies, Vol. 5 No. 4, pp. 337-348.

Goetz, S.J., Partridge, M., Deller, S.C. and Fleming, D.A. (2010), "Evaluating US", Rural Entrepreneurship Policy, Vol. 40 No. 1, pp. 20-33.

Katz, J. and Gartner, W.B. (1988), "Properties of emerging organizations", Academy of Management Review, Vol. 13 No. 3, pp. 429-441.

Stathopoulou, S., Psaltopoulos, D. and Skuras, D. (2004), "Rural entrepreneurship in Europe", International Journal of Entrepreneurial Behavior \& Research, Vol. 10 No. 6, pp. 404-425. 